\title{
"If everyone else is having this talk with their doctor, why am I not having this talk with mine?": The experiences of sexuality and sexual health education of young women with spina bifida.
}

\author{
Courtney S. Streur, MD ${ }^{1,3,4}$, Christine L. Schafer, BS ${ }^{1}$, Valerie P. Garcia ${ }^{1}$, Elisabeth H. Quint, \\ $\mathbf{M D}^{2}$, David E. Sandberg, $\mathrm{PhD}^{3}$, and Daniela A. Wittmann, $\mathrm{PhD}^{1,4}$ \\ 1. University of Michigan, Department of Urology, Ann Arbor, MI \\ 2.University of Michigan, Department of Obstetrics and Gynecology, Ann Arbor, MI \\ 3.University of Michigan, Department of Pediatrics, Susan B. Meister Child Health Evaluation and \\ Research Center, Ann Arbor, MI \\ 4. University of Michigan, Department of Urology, Dow Division of Health Services Research, Ann \\ Arbor, MI
}

\section{Structured Abstract}

Background: Women with spina bifida are sexually active, but most never discuss this topic with providers.

\begin{abstract}
Aim: The objective of this study was to determine what women with spina bifida understand about their sexual health, how they learned about it, what questions they have, and their experiences with their sexuality.
\end{abstract}

\begin{abstract}
Methods: For this qualitative study, women with spina bifida ages 16 and older without marked developmental delay were individually interviewed. Twenty-five women with spina bifida participated (mean age 27.1 years, range 16-52). Interviews were independently coded for themes by 3 reviewers, using Grounded Theory, with disagreements resolved by consensus.
\end{abstract}

Outcomes: We identified overlapping themes regarding the women's perception and experience of their sexuality and sexual health education.

Results: Seventeen of the 25 (68\%) participants had been or were currently sexually active. Five themes emerged regarding their understanding of their sexuality and their sexual experiences: 1) being perceived as asexual, 2) sources for sex education, 3) need for spina bifida -specific sex education, 4) impact of spina bifida -specific features on sexual encounters, and 5) perceived relationship between low sexual self-confidence and risk for sexual assault.

Clinical Implications: Women with spina bifida are sexual beings, but perceived as asexual by providers, which prevents them from getting adequate sexual health education and leaves them with misconceptions, unanswered questions, and vulnerable to sexual abuse. 
Strengths \& Limitations: The strengths of this study include the diversity of women interviewed, including their age, severity of disability, and experiences with their sexuality, as well as the ability to reach thematic saturation. The limitation of this study is that most women received treatment at a single Midwestern tertiary referral center in the United States.

Conclusion: Including sexual health discussions in the usual care of women with spina bifida is critical to enhancing their sexual confidence and experience and preventing sexual abuse.

\section{Keywords}

spina bifida; sexuality; sex education; sexual abuse

\section{Introduction}

Although up to $55 \%$ of young female adults with spina bifida are sexually active and $92 \%$ hope to find a partner, as few as $5 \%$ of these women have ever talked about sex with any healthcare provider ${ }^{1-7}$. Many women with disabilities assume that sex education provided in schools or by family members does not apply to them, but also have difficulty finding information specific to them from less formal sources such as the media or their peers. ${ }^{8,9}$ Without applicable sex education, they are vulnerable to potentially harmful misconceptions, such as assuming they cannot get pregnant, and reduced quality of life from their spina bifida-specific sexual health concerns such as incontinence during intercourse not being addressed. ${ }^{6,10-13}$

This problem is due primarily to the lack of research on the sexuality of women with spina bifida. Most research in the spina bifida population is focused on men. ${ }^{14}$ Little is known about their understanding of their sexuality, nor their sexual experiences. In our previous research, we found that pediatric urologists who regularly care for young women with spina bifida report that they lack a basic understanding of this topic and thus avoid discussing it with patients due to fear of being asked questions they cannot answer. ${ }^{15}$

In this context, we sought to determine women with spina bifida's understanding of their own sexuality, how they have learned about it, and how it has affected their sexual experiences. Given the limited research on this topic, we utilized a qualitative methodology to conceptualize what was important to these women through their own voices.

\section{Materials and Methods}

This was an exploratory qualitative study that employed purposive, criterion sampling. Institutional Review Board approval from a large Midwestern tertiary referral center was obtained prior to participant recruitment.

\section{Research Team}

The research team was composed of four members: a pediatric urologist who cares for women with spina bifida (CSS), a certified sex therapist, licensed social worker, and sexual health researcher with expertise in qualitative research methodology (DW), and two undergraduate students (CS and VG). 


\section{Study Sample}

Women with spina bifida ages 16 years and older were eligible to participate. They were excluded if they were non-English speaking or had marked developmental delay as determined by their medical record or a limited their ability to understand or answer questions independently. Participants did not have to be currently or previously sexually active to participate. Twenty-five women with spina bifida, ages 16-52 years (mean=27.1, $\mathrm{SD}=8.1$ ), participated in the study.

\section{Recruitment}

Using the electronic medical record, we identified all women followed at our institution with the diagnosis of spina bifida or spina bifida occulta (ICD-10 Codes: Q05.9, Q05.4, Q05.8. ICD-9 Codes: 741.91, 741.00) without a diagnosis of marked developmental delay. Letters were sent to 132 eligible women explaining the goal of the study and inviting them to participate in person or by telephone with a $\$ 25$ incentive.

Additionally, a Facebook advertisement inviting women to learn about the study was run for a total of 6 weeks. The advertisement directed women to a description of the project on our institution's research webpage.

Interested women who contacted the research coordinator were given additional details about the study and, if interviewed by phone, instructed to be in a private location during the interview. Twenty-four women were recruited from letters and one was recruited through Facebook. All women who expressed interest in the study participated except for one who was deemed ineligible because she was unsure if she had spina bifida or another neurologic condition. Consent was obtained through a secure online program (REDCap®) or over the phone at the time of the interview.

\section{Data Collection}

Semi-structured interview guides were developed, based on the investigators' clinical experience with spina bifida (CSS) and sexual health research (DW) and then iteratively modified during the course of the project, based on new information learned from participants (Appendix A). The questions were open-ended. Examples of questions included, "tell me about how you first learned about sex and having babies?" and "what about sex may be different for you than for someone without spina bifida?". The one-on-one interviews were conducted by one of three investigators (CSS, CS, VG). Interviews were recorded and transcribed verbatim. Each participant was assigned a study ID number to ensure anonymity. Field notes were collected, documenting interviewers' impression of patients' comfort and openness during the discussion.

\section{Data Analysis}

The interviews were analyzed by three authors (CSS, CS, DW) independently, using Grounded Theory procedures. ${ }^{16}$ Grounded Theory is a methodology utilized for exploratory qualitative studies such as this where there is no foundational knowledge or existing assumptions. The qualitative data collected is then allowed to formulate new ideas or concepts based on recurring themes. 
The analysts independently read through each transcript, highlighting quotes related to the research questions that were meaningful. Each quote was then summarized with a short descriptive phrase, or "open code", that conveyed the concept of the quote. The analysts then met together to compare the quotes included and to ensure all meaningful quotes were captured. Next, we combined related open codes into "axial codes", or short phrases or themes that describe how the quotes were related. Axial codes were categorized into higher level constructs, or overarching themes (Table 1). Three coders reviewed each interview together and discussed the codes until consensus was reached. Thematic saturation was reached after 25 interviews. At this point, no new themes or concepts were identified from interviews, indicating that all major themes related to the research question had been discovered. Trustworthiness of the data was assured by the ability to reach thematic saturation, diversity of the disability severity of the participants, investigator's experience studying sexual health (DW), caring for patients with spina bifida (CSS), separate coding by the investigators, rigorous discussion of the findings and consensus on the results. ${ }^{17,18}$ Demographic data was analyzed using the Chi-square test.

\section{Results}

Of the twenty-five participants, twenty-four defined "sexual activity" as partnered intercourse between a man and woman; one participant defined it as "kissing, oral sex, anal sex, penetration or stimulation" with any partner (Participant 16, 22 years). Seventeen women $(68 \%)$ had experienced partnered sexual intercourse (16 heterosexual, 1 homosexual). There was no significant difference in sexual activity between women who did $(8 / 13)$ or did not require assistance for ambulation $(8 / 11)(\mathrm{p}=0.56)$. Similarly, there was no significant difference in sexual activity between women who were on a bladder management program of clean intermittent catheterization or urostomy (9/15) or had no intervention or medication only $(8 / 10)(\mathrm{p}=0.29)$.

Interviews findings revealed five themes that characterized participants' understanding and experiences of their sexuality: 1) being perceived as asexual, 2) inadequate sources for sex education, 3) need for spina bifida -specific sex education, 4) impact of spina bifida -specific features on sexual encounters, and 5) perceived relationship between low sexual selfconfidence and risk for sexual assault (Table 3).

\section{Being Perceived as Asexual}

Women with spina bifida struggled with the feeling that they were seen as asexual by society. Specifically, they felt that most doctors did not think they had any interest in or could be sexually active. Additionally, they felt that potential partners did not view them as sexual beings.

"I think that [it] is one of those things that's not really discussed with spina bifida because they deem us as oh... you won't have sex." Participant 18, 27 years

"I made an appointment with just some random doctor... and he said, 'so why are you here?' And I said, 'for birth control.' And he's like, 'but what do you mean?' And I was like, 'well, because I don't like having babies, like I' $m$ on a college track...' 'But like, you're in a wheelchair.' And I was like, 'yeah...' And he's like, 
'you can't stand.' And I was like, 'do you stand when you have sex?'” Participant 10,29 years

“...I don't think that men look at me and think I'm pretty... I always worry when a guy sees me is he seeing me or is he seeing my chair?" Participant 23, 36 years

This stigma is not only painful for the women to experience, but it also makes it difficult for them to get the education and health care that they need.

\section{Inadequate Sources for Sexual Health Education}

Women described learning about sex gradually from sources that did not include information about spina bifida and sexuality. Most women initially received sex education in the middleschool years, either at school (19 women) and/or from their parents (12 women). This education was described as overly basic and not specific to them. Twelve women talked to their primary care doctors, gynecologists, or specialists about some aspect their sexual or reproductive health, but for most, it was limited to managing their menstruation without mention of their sexual health. Four women described helpful conversations about spina bifida-specific concerns with a provider, such as a doctor, nurse, or physical therapist. This was usually prompted by the patient. Women also reported learning about sexuality from their peers or siblings, online, media, and their own experience.

"Yes, [sex education] was very basic stuff like what is birth control, what types of birth control there are, sexually transmitted diseases, just not into the... very detailed information.” Participant 19, 32 years

"Definitely seeing a physical therapist about different positions and such was very helpful." Participant 12, 30 years

"I've just been basically figuring things out on my own as I got older." Participant 1,26 years

No matter where women learned about their sexual health, most reported that the education was not adequate to prepare them for sexual activity in the context of spina bifida. Some slowly acquired more relevant information about their sexuality from their own experience, but rarely from health care providers.

\section{Need for Spina Bifida-Specific Sexual Education}

Women recognized the gap between general sex education and their own experience and felt they needed more specific information relevant to people with spina bifida. Many felt that what they learned in sex education did not apply to them at all, with most unsure if they could get pregnant. Only half of the sexually active women used contraception. Others wondered how their disability would impact sex or if sex was safe for them. They described limited resources to learn about sex specific to spina bifida.

"I was just always curious if I was going to be even normal compared to other girls... I thought I was just different in general." Participant 20, 35 years

“...I remember the first time I had my period [at age 8]... I thought I was bleeding to death.” Participant 23, 36 years 
“...I feel like all of us are scared to even think about that type of stuff because we can't think about it being normal... there's a lot of fear that comes with thinking about being sexually active..." Participant 14, 23 years

The women knew they did not understand their sexuality. Some struggled with potentially dangerous misconceptions, fears, and unanswered questions.

\section{Impact of Spina Bifida-Specific Features on Sexual Encounters}

Women with spina bifida reported encountering several challenges in a sexual relationship unique to their disability. They had to be mindful of sexual positioning and activities due to hip and back pain, anatomical considerations such as vaginal prolapse, potential leakage of their bladder and bowel during sex, and diminished sensation. Some women complained that the need to empty their bladder and bowels before sex inhibited their ability to be spontaneous.

"[Spina bifida has] affected like my, especially in my hips and in my back, that sometimes sex has been an uncomfortable thing." Participant 19, 32 years

"...sex used to really hurt, so until I started doing it what they call doggy style... That's how my gynecologist explained it after looking at my anatomy in there... I [have]... ureterovaginal prolapse..." Participant 18, 27 years

"And that is always a worry for me, because when my bladder lets go, it lets go. And it's happened also with my bowel and that's embarrassing..." Participant 22, 25 years

“...if I'm walking a lot or if I'm sitting for a long period of time then I'll have like more numbness than usual and then like obviously I don't enjoy it...” Participant 3 , 24 years

Those women who experienced intercourse with a supportive partner found this relieved their anxieties about how spina bifida impact a sexual experience.

"I always have to self-cath right before or my bladder will leak, which has happened a couple times and my husband and he's like eh whatever, I don't care."

Participant 20, 35 years

Sexually active women with spina bifida experienced some physical differences and difficulties during intimacy secondary to their disability. They found that having a supportive partner willing to adapt with positions and not bothered by incontinence makes intercourse more enjoyable.

\section{Perceived Relationship Between Low Sexual Self-confidence and Risk for Sexual Assault}

Most women reported having low sexual self-confidence due to a poor body image. Women were particularly self-conscious of their backs, buttocks, and stomas. They worried about how they compared to able-bodied women and if they would be embarrassed during sex.

“...when I was younger I felt very ashamed of my body and as I've grown up that hasn't changed a whole lot... my scar is right above my butt so it was a little lumpy..." Participant 16, 22 years 
"I do not feel comfortable talking about my differences physically and internally... the Mitrofanoff [bladder catheterization channel] and then the whole butt crack thing... that's why I always had sex in the dark a lot." Participant 18, 27 years “...because I don't have the stability in my pelvic area... I'm not able to be as good as a normal able-bodied person because they can move their pelvis..." Participant 22,35 years

Improvement in sexual self-confidence occurred for women who found committed, supportive, and affirming partners with whom they felt comfortable. Those who did have such an experience continued to struggle with sexual self-confidence, regardless of their age.

"Like I'm married now... and I have been with him since I was fifteen years old so like he gets it and I tell him everything and I tell him like okay this is not working. Here do it like this. Like that's not working, because I'm comfortable with him..." Participant 3, 24 years

"I've always been really insecure about [the scars on my back] so thinking you're unbeautiful can... lower your self-esteem and make your sex life extra awkward as well." Participant 10, 29 years

Women reported that the combination of this low sexual self-confidence and being seen as asexual made them vulnerable to sexual assault. Three shared personal stories of sexual abuse, although this was not purposely elicited in the interviews. Some tolerated this abuse out of a desire to be viewed as sexually desirable. Another woman described becoming sexually promiscuous out of loneliness and a desire to be loved, which eventually led to her experience a sexual assault.

“... I was sexually assaulted and I thought that was the only form of sexual contact that I would get because when you don't talk to people with disabilities about sex you give them this feeling like disabled people won't have sex because no one's going to want you so then you start to just accept the way that anyone treats you as long as they're looking at you as a sexual being...” Participant 10, 29 years

“...I just felt so alone and I wanted that feeling, I don't think I really wanted sex, I wanted someone to love me." Participant 25, 52 years

"And I think another thing that I know I did is that I was just trying to satisfy a person, so if it hurt me it didn't matter..." Participant 25, 52 years

Low sexual self-confidence was experienced nearly universally, although some reported that this improved with experiences with supportive partners. These women explained that the combination of low self-image and their desire to be seen as sexual beings made them vulnerable to abuse.

\section{Discussion}

Given the paucity of research on the sexuality of women with spina bifida, the purpose of this exploratory qualitative study was to discover women with spina bifida's perception of their sexuality, exposure to sex education, and personal sexual experiences. Key findings 
included that women: 1) struggle with being perceived as asexual by their doctors and peers; 2) received inadequate sex education from school, parents, and providers; 3) lacked understanding about their sexuality and sexual health, leading to potentially harmful behaviors such as not using contraception; 4) had difficulties during intercourse specific to their disability, such as with movement, incontinence, and sensation; and 5) experienced low sexual self-esteem that made them vulnerable to sexual coercion and abuse.

These findings are consistent with the reported literature. A study of 504 women with disabilities revealed that most assumed what sexual education they learned in school did not apply to them due to their disability. ${ }^{8}$ A study of youths with spina bifida showed that $74 \%$ rated their knowledge of sexual health and spina bifida as "poor" or "extremely poor." Most had unanswered questions, such as whether or not they could get sexually transmitted infections or if they could give their partner spina bifida through intercourse. ${ }^{4}$

The stereotype that women with disabilities are asexual has potentially harmful repercussions. It prevents them from accessing appropriate sexual health education and care because providers do not offer it. ${ }^{8}$ Indeed, they are less likely to get routine gynecologic care such as pap smears compared to their able-bodied counterparts. ${ }^{19}$ Perhaps related to this lack of education, as few as $9 \%$ of sexually active young adults with spina bifida use birth contraception compared to $81 \%$ of their able-bodied peers. ${ }^{20,21}$ Additionally, this stereotype is both frustrating and painful to women. ${ }^{8,22}$ One woman in this study felt this stigma made her especially vulnerable to sexual abuse, because she was thankful that someone viewed her as sexual.

The increased risk of sexual abuse in women with disabilities has also been documented, although never specifically among women with spina bifida. Women with severe disabilities are four times more likely to be sexually assaulted than women without disabilities. ${ }^{23}$ Women with disabilities are also more likely to experience sexual coercion and noncontact unwanted sexual interactions. ${ }^{24}$ This risk is thought to be related to their low self-esteem, fear of being alone, and physical dependency. ${ }^{25}$ In this study, we found that women's loneliness, desire to be loved, the lack of sex education by providers, and desire to be seen as sexual beings made them vulnerable.

The strengths of this study include the number of sexually active women with different severities of spina bifida who participated, the openness of the participants, the ability to reach thematic saturation, and the development of new concepts. The limitation of this study is the recruitment from a single Midwestern tertiary referral center in the United States. However, most also received care at other centers, allowing for a more diverse perspective. Additionally, 11/25 patients required no assistance for ambulation and 10/25 patients did not require (or admitted to not being compliant with) intermittent catheterization, indicating that this population may not be representative of those women seen at most adolescent and adult spina bifida clinics. Nonetheless, their experience with sexuality and self-confidence was impacted by their diagnosis, indicating that these issues still need to be addressed no matter the severity of their disability. We plan to next further explore these themes in a broader group of women with a subsequent survey. Finally, we did not specifically ask women if 
they participate in solo sexual activity such as masturbation, instead focusing on partnered activity, which may limit our understanding of their sexual experiences. .

\section{Conclusions}

This study discovered foundational concepts and issues critical to understanding women with spina bifida's perception and experiences with their sexuality as well as their sexual health education. For providers caring for this population, the findings of this study identify the importance of recognizing that all women are sexual and therefore need sexual health education in order to prevent potentially harmful misconceptions, address concerns specific to their disability, and optimize their sexual experiences and self-confidence. Additionally, this study demonstrates that addressing sexuality may help decrease sexual coercion and abuse. Information from this study will serve to inform the development of an educational intervention for women with spina bifida and the providers who care for them.

\section{Acknowledgement:}

This research was supported by the Society of Women in Urology's Elisabeth Pickett Research Award and by a T-32 Training Grant from the NIDDK.

Funding: This research was funded by the Society of Women in Urology's Elisabeth Pickett Research Award and a T-32 training grant from the National Institute of Health's National Institute of Diabetes and Digestive and Kidney Diseases (grant number 5T32DK007782-17).

\section{Appendix A: Interview guide for young women with SB Background questions.}

1. How old are you?

2. Do you use any assistance for walking around?

3. How do you manage your bladder (ie: do you void normally, catheterize through your urethra or through a bladder channel, or have a urostomy)?

4. Are you currently using any form of birth control?

5. Can you tell me about when you were diagnosed with spina bifida?

6. What has your spina bifida treatment been like?

7. How does your spina bifida affect your daily life?

\section{Her knowledge about sexuality and reproductive health and how she learned.}

1. Tell me about how you first learned about sex and having babies?

PROBES: Parents

Internet

Teacher at school 
Friends

Healthcare provider

TV

Other

FU: How old were you when you first learned about it?

FU (school): What parts about what you learned did you think applied to you? What parts did you think didn't apply to you?

PROBES: Periods

Getting pregnant

STIs

Fertility

Birth control

2. Has anyone ever talked to you about getting a female exam or seeing a female doctor?

PROBES: do you know what gynecologists do?

Ask questions about menstruation

Pelvic exams

Vaccination to prevent HPV

Pap smears to check for HPV

Counseling about contraception, like the pill, condoms and other ways of preventing pregnancy

Checking for STIs

FU: Do you know when you are supposed to see them?

3. Can you tell me what your doctor has talked to you about when it comes to sex?

4. Can you tell me what your doctor has talked to you about when it comes to having babies?

\section{IF THEY HAVE TALKED TO A DOCTOR ABOUT SEXUAL AND REPRODUCTIVE HEALTH:}

5. What kind of doctor (or doctors) did you discuss it with?

PROBES: Urologist

Gynecologist

Pediatrician/primary care doctor

J Sex Med. Author manuscript; available in PMC 2020 June 01. 
6. Do you remember about how old you were when they talked about it for the first time?

7. How did you feel about the timing of when they talked to you?

PROBES: Were you interested in talking about it?

Had you already been sexually active or been interested in being sexually active before they brought it up?

Did you feel it was too early or too late?

8. What was it like discussing sex and having babies with your doctor the first time?

Was it comfortable?

Can you tell me what made it comfortable or uncomfortable?

What questions did you have after the talk that weren't answered?

What did you feel was left out?

What do you wish was done differently?

9. What has it been like discussing sex and babies with your doctor since that time?

PROBES: What kind of discussions about sex have you had since that time?

\section{IF THEY HAVE NOT TALKED TO A DOCTOR ABOUT SEXUAL AND REPRODUCTIVE HEALTH:}

10. How does it make you feel not having your doctor talk to you about sexual and reproductive health?

PROBES: Did you feel like it would be ok to bring it up yourself?

Do you feel like your doctor understands you and your concerns when it comes to sexual and reproductive health?

\section{ALL WOMEN}

11. If you could tell your doctor how to teach a young woman with spina bifida about sex for the first time, what would you say?

PROBES: Age

Should parents be there

Who should bring it up first?

What should they talk about?

How can they make it more comfortable?

12. Does anything keep you from talking to your doctor about sex now?

J Sex Med. Author manuscript; available in PMC 2020 June 01. 
PROBES: Embarrassment

Feeling rushed by doctor

How are they at making you feel like your concerns are legitimate?

How are they at answering your questions?

13. Is there anything you wish you could talk about with your doctor but haven't when it comes to sex?

PROBES: Difficulties in having sex

Worried about getting a PAP smear or STD testing

14. If you could tell your doctor how to teach a young woman with spina bifida about getting pregnant and having babies for the first time, what would you say?

PROBES: Age

How should the parents be handled? What parts should they be present for and what parts should be done with only the patient in the room?

Who should bring it up first?

What should they talk about?

How can they make it more comfortable?

15. Does anything keep you from talking to your doctor about getting pregnant and having babies now?

PROBES: Embarrassment

Feeling rushed by doctor

How are they at making you feel like your concerns are legitimate?

How are they at answering your questions?

16. Is there anything you wish you could talk about with your doctor but haven't when it comes to getting pregnant and having babies?

PROBES: Ability to get pregnant

Risk of spina bifida in your baby

How the pregnancy may impact your health

\section{Her own experience}

1. Have you ever thought about how sex and having an intimate relationship may be different for you than for someone without SB?

PROBES: Would it be similar or different from people who do not have SB

If different, what would be different - how you can move, what feels good

If different, would anything get in the way - difficulties with positions

J Sex Med. Author manuscript; available in PMC 2020 June 01. 
If different, what would be different about being pregnancy?

2. What about sex may be different for you than for someone without spina bifida?

PROBES: sensation/feeling

Moving

\section{Sources}

1. Cardenas DD, Topolski TD, White CJ, McLaughlin JF, Walker WO. Sexual functioning in adolescents and young adults with spina bifida. Archives of physical medicine and rehabilitation. 2008;89(1):31-35. [PubMed: 18164327]

2. Game X, Moscovici J, Guillotreau J, Roumiguie M, Rischmann P, Malavaud B. Sexual function of young women with myelomeningocele. J Pediatr Urol. 2014;10(3):418-423. [PubMed: 23992838]

3. Verhoef M, Barf HA, Vroege JA, et al. Sex education, relationships, and sexuality in young adults with spina bifida. Archives of physical medicine and rehabilitation. 2005;86(5):979-987. [PubMed: 15895345]

4. Sawyer SM, Roberts KV. Sexual and reproductive health in young people with spina bifida. Developmental medicine and child neurology. 1999;41(10):671-675. [PubMed: 10587043]

5. Lassmann J, Garibay Gonzalez F, Melchionni JB, Pasquariello PS Jr., Snyder HM 3rd. Sexual function in adult patients with spina bifida and its impact on quality of life. The Journal of urology. 2007;178(4 Pt 2):1611-1614. [PubMed: 17707040]

6. Cromer BA, Enrile B, McCoy K, Gerhardstein MJ, Fitzpatrick M, Judis J. Knowledge, attitudes and behavior related to sexuality in adolescents with chronic disability. Developmental medicine and child neurology. 1990;32(7):602-610. [PubMed: 2143989]

7. Gatti C, Del Rossi C, Ferrari A, Casolari E, Casadio G, Scire G. Predictors of successful sexual partnering of adults with spina bifida. The Journal of urology. 2009;182(4 Suppl):1911-1916. [PubMed: 19695634]

8. Nosek MA HC, Rintala DH, Young ME, Chanpong GF. National study of women with physical disabilities: final report. Sexuality and disability. 2001;19(1):5-39.

9. Esmail S, Darry K, Walter A, Knupp H. Attitudes and perceptions towards disability and sexuality. Disability and rehabilitation. 2010;32(14):1148-1155. [PubMed: 20131952]

10. Blum RW, Resnick MD, Nelson R, St Germaine A. Family and peer issues among adolescents with spina bifida and cerebral palsy. Pediatrics. 1991;88(2):280-285. [PubMed: 1861926]

11. Akre C, Light A, Sherman L, Polvinen J, Rich M. What young people with spina bifida want to know about sex and are not being told. Child: care, health and development. 2015;41(6):963-969.

12. Rowen TS, Stein S, Tepper M. Sexual health care for people with physical disabilities. The journal of sexual medicine. 2015;12(3):584-589. [PubMed: 25739683]

13. Valencia LS, Cromer BA. Sexual activity and other high-risk behaviors in adolescents with chronic illness: a review. Journal of pediatric and adolescent gynecology. 2000;13(2):53-64. [PubMed: 10869964]

14. de Vylder A, van Driel MF, Staal AL, Weijmar Schultz WC, Nijman JM. Myelomeningocele and female sexuality: an issue? European urology. 2004;46(4):421-426; discussion 426-427. [PubMed: 15363553]

15. Streur CS, Schafer CL, Garcia VP, Wittmann DA. “I Don't Know What I'm Doing... I Hope I'm Not Just an Idiot": The Need to Train Pediatric Urologists to Discuss Sexual and Reproductive Health Care With Young Women With Spina Bifida. The journal of sexual medicine. 2018;15(10): 1403-1413. [PubMed: 30195565]

16. Charmaz K Construction Grounded Theory: A Practical Guide Through Qualitative Analysis. 2 ed: London, Thousand Oaks, New Delhi: SAGE Publications; 2006.

17. Moser A, Korstjens I. Series: Practical guidance to qualitative research. Part 3: Sampling, data collection and analysis. The European journal of general practice. 2018;24(1):9-18. [PubMed: 29199486] 
18. Korstjens I, Moser A. Series: Practical guidance to qualitative research. Part 4: Trustworthiness and publishing. The European journal of general practice. 2018;24(1):120-124. [PubMed: 29202616]

19. McRee AL, Haydon AA, Halpern CT. Reproductive health of young adults with physical disabilities in the U.S. Preventive medicine. 2010;51(6):502-504. [PubMed: 20851142]

20. Lee NG, Andrews E, Rosoklija I, et al. The effect of spinal cord level on sexual function in the spina bifida population. J Pediatr Urol. 2015;11(3):142.e141-146. [PubMed: 25864616]

21. Abma JC, Martinez GM. Sexual Activity and Contraceptive Use Among Teenagers in the United States, 2011-2015. National health statistics reports. 2017(104):1-23.

22. Zitzelspina bifidaerger H (In)visibility: accounts of embodiment of women with physical disabilities and differences. Disability \& Society. 2005;20(4):389-403.

23. Casteel C, Martin SL, Smith JB, Gurka KK, Kupper LL. National study of physical and sexual assault among women with disabilities. Injury prevention : journal of the International Society for Child and Adolescent Injury Prevention. 2008;14(2):87-90. [PubMed: 18388227]

24. Basile KC, Breiding MJ, Smith SG. Disability and Risk of Recent Sexual Violence in the United States. American journal of public health. 2016;106(5):928-933. [PubMed: 26890182]

25. Plummer SPINABIFIDA, Findley PA. Women with disabilities' experience with physical and sexual abuse: review of the literature and implications for the field. Trauma, violence $\&$ abuse. 2012;13(1):15-29. 
Table 1.

Example of the coding process.

\begin{tabular}{|c|c|c|c|}
\hline Quote & Open Code & Axial Code & Theme \\
\hline $\begin{array}{l}\text { "In fact, when I was little, I specifically remembering my } \\
\text { pediatrician not even bringing up sex at all as a subject, and } \\
\text { knowing that my peers were getting at least some information from } \\
\text { their doctors when I wasn't.". }\end{array}$ & $\begin{array}{l}\text { Pediatrician did not talk to } \\
\text { her about sex but did talk to } \\
\text { peers }\end{array}$ & $\begin{array}{l}\text { Doctors treated her } \\
\text { as asexual }\end{array}$ & $\begin{array}{l}\text { Being } \\
\text { perceived as } \\
\text { asexual }\end{array}$ \\
\hline $\begin{array}{l}\text { "I can think of } 2 \text { guys that I dated in the past that I really don't } \\
\text { think... that they looked at me as a sexual person, as a person with } \\
\text { sexual desires, and I'm human so I have those." }\end{array}$ & $\begin{array}{l}\text { Dated } 2 \text { men who did not } \\
\text { view her as sexual }\end{array}$ & $\begin{array}{l}\text { Boyfriends treated } \\
\text { her as asexual }\end{array}$ & $\begin{array}{l}\text { Being } \\
\text { perceived as } \\
\text { asexual }\end{array}$ \\
\hline $\begin{array}{l}\text { "Because I felt like because doctors never saw me that way, not that } \\
\text { my doctor should see me as pretty or anything but I just felt like } \\
\text { they had this stigma on me." }\end{array}$ & $\begin{array}{l}\text { Felt that doctors did not view } \\
\text { her as someone interested in } \\
\text { sex }\end{array}$ & $\begin{array}{l}\text { Doctors treated her } \\
\text { as asexual }\end{array}$ & $\begin{array}{l}\text { Being } \\
\text { perceived as } \\
\text { asexual }\end{array}$ \\
\hline
\end{tabular}


Table 2.

Participant demographics.

\begin{tabular}{|c|c|c|c|c|c|c|}
\hline Patient & Age & $\begin{array}{l}\text { Bladder } \\
\text { management }\end{array}$ & $\begin{array}{l}\text { Ambulatory } \\
\text { Status }\end{array}$ & $\begin{array}{l}\text { Current or } \\
\text { previous } \\
\text { sexual } \\
\text { activity }\end{array}$ & $\begin{array}{l}\text { Spoke to a } \\
\text { doctor about } \\
\text { sex before } \\
\text { having sex }\end{array}$ & $\begin{array}{l}\text { Current } \\
\text { partner or } \\
\text { desire for a } \\
\text { partner }\end{array}$ \\
\hline 1 & 26 & None & No assistance & $\mathrm{Y}$ & $\mathrm{N}$ & $\mathrm{Y}$ \\
\hline 2 & 22 & Medication only & UNK & $\mathrm{Y}$ & UNK & $\mathrm{Y}$ \\
\hline 3 & 24 & None & No Assistance & $\mathrm{Y}$ & UNK & $\mathrm{Y}$ \\
\hline 4 & 26 & None & No assistance & $\mathrm{Y}$ & $\mathrm{N}$ & $\mathrm{Y}$ \\
\hline 5 & 19 & None & No assistance & $\mathrm{N}$ & $\mathrm{N}$ & $\mathrm{Y}$ \\
\hline 6 & 23 & CIC (bladder channel) & Wheelchair & $\mathrm{N}$ & $\mathrm{N}$ & $\mathrm{N}$ \\
\hline 7 & 21 & CIC (urethra) & No assistance & $\mathrm{N}$ & $\mathrm{N}$ & $\mathrm{N} / \mathrm{Y}$ \\
\hline 8 & 32 & None & No assistance & $\mathrm{Y}$ & $\mathrm{N}$ & $\mathrm{Y}$ \\
\hline 9 & 19 & CIC (bladder channel) & Wheelchair & $\mathrm{Y}$ & $\mathrm{N}$ & $\mathrm{Y}$ \\
\hline 10 & 29 & None & AFOs/Wheelchair & $\mathrm{Y}$ & $\mathrm{Y}$ & $\mathrm{Y}$ \\
\hline 11 & 23 & CIC (urethra) & Crutches/Wheelchair & $\mathrm{N}$ & N/A & $\mathrm{Y}$ \\
\hline 12 & 30 & None & No assistance & $\mathrm{Y}$ & $\mathrm{N}$ & $\mathrm{Y}$ \\
\hline 13 & 16 & CIC (urethra) & AFOs & $\mathrm{N}$ & $\mathrm{N}$ & $\mathrm{Y}$ \\
\hline 14 & 23 & CIC (bladder channel) & Crutches & $\mathrm{Y}$ & $\mathrm{Y}$ & $\mathrm{Y}$ \\
\hline 15 & 19 & CIC (bladder channel) & Wheelchair & $\mathrm{N}$ & $\mathrm{N}$ & $\mathrm{N}$ \\
\hline 16 & 22 & CIC (urethra) & AFOs & $\mathrm{N}$ & UNK & $\mathrm{Y}$ \\
\hline 17 & 17 & CIC (urethra) & No assistance & $\mathrm{Y}$ & N/A & $\mathrm{Y}$ \\
\hline 18 & 27 & CIC (bladder channel) & Wheelchair & $\mathrm{Y}$ & $\mathrm{Y}$ & $\mathrm{Y}$ \\
\hline 19 & 32 & None & No assistance & $\mathrm{Y}$ & $\mathrm{N}$ & $\mathrm{Y}$ \\
\hline 20 & 35 & CIC (urethra) & No assistance & $\mathrm{Y}$ & $\mathrm{N}$ & $\mathrm{Y}$ \\
\hline 21 & 33 & None & No assistance & $\mathrm{N}$ & $\mathrm{N}$ & $\mathrm{Y}$ \\
\hline 22 & 35 & CIC & Wheelchair & $\mathrm{Y}$ & $\mathrm{Y}$ & $\mathrm{Y}$ \\
\hline 23 & 36 & Urostomy & Wheelchair & $\mathrm{Y}$ & $\mathrm{Y}$ & $\mathrm{Y}$ \\
\hline 24 & 36 & CIC (bladder channel) & AFOs & $\mathrm{Y}$ & $\mathrm{Y}$ & $\mathrm{Y}$ \\
\hline 25 & 52 & Urostomy & Wheelchair & $\mathrm{Y}$ & $\mathrm{N}$ & $\mathrm{Y}$ \\
\hline
\end{tabular}

CIC: clean intermittent catheterization; AFOs: ankle foot orthosis; UNK- unknown 
Table 3.

Development of themes.

\begin{tabular}{|l|c|c|}
\hline Theme & Number of Quotes & Number of Participants \\
\hline Being perceived as asexual & 49 & 14 \\
\hline Sources for sex education & 106 & 24 \\
\hline Need for SB specific sex education & 202 & 25 \\
\hline Impact of SB symptoms on sexual encounters & 180 & 22 \\
\hline Sexual Confidence and Risk of Sexual Assault & 86 & 22 \\
\hline
\end{tabular}

